\title{
Natural Transformation of Oral Streptococci by use of Synthetic
}

\section{Pheromones}

Gabriela Salvadori $^{1}$, Roger Junges ${ }^{1}$, Rabia Khan ${ }^{1}$, Heidi A. Åmdal ${ }^{1}$, Donald A. Morrison ${ }^{2}$, Fernanda C. Petersen ${ }^{1}$

${ }^{1}$ Department of Oral Biology, Faculty of Dentistry, University of Oslo, Norway

${ }^{2}$ Department of Biological Sciences, College of Liberal Arts and Sciences, University of Illinois at Chicago, USA

Corresponding author: Fernanda Cristina Petersen

Mailing address: Department of Oral Biology, Faculty of Dentistry, University of Oslo, P.O. Box 1052 Blindern, N-0316, Norway.

Phone: (47) 22840312

Fax: (47) 22840302

E-mail: f.c.petersen@odont.uio.no 


\begin{abstract}
The discovery that Streptococcus pneumoniae uses a competence-stimulating peptide (CSP) to induce competence for natural transformation, and that other species of the mitis and the anginosus streptococcal groups use a similar system, has expanded the tools to explore gene function and regulatory pathways in streptococci. Two other classes of pheromones have been discovered since then, comprising the bacteriocin-inducing peptide class found in Streptococcus mutans (also named CSP, although different from the former) and the SigX-inducing peptides (XIP), in the mutans, salivarius, bovis, and pyogenes groups of streptococci. The three classes of peptide pheromones can be ordered from peptide synthesis services at affordable prices, and used in transformation assays to obtain competent cultures consistently at levels usually higher than those achieved during spontaneous competence. In this chapter, we present protocols for natural transformation of oral streptococci that are based on the use of synthetic pheromones, with examples of conditions optimized for transformation of S. mutans and Streptococcus mitis.
\end{abstract}

Key words: oral streptococcus; Streptococcus mutans, Streptococcus mitis, competence, natural transformation, competence-stimulating peptide (CSP), SigX-inducing peptide (XIP). 


\section{Introduction}

Natural genetic transformation is widespread in oral streptococci, including the mutans, the salivarius, the mitis, and the anginosus groups $[1,2,3]$. The mechanisms depend on streptococci entering competence, a physiological state triggered by pheromones, and characterized by the induction in expression of several gene clusters, including those essential for DNA uptake and recombination.

Streptococcal competence pheromones can be divided into three classes: (1) competence stimulating peptides (CSPs), (2) SigX-inducing peptides (XIPs), and (3) bacteriocininducing peptides with competence-inducing activity. The first class, used by the mitis and anginosus groups, is sensed by a two-component system comprising a histidine kinase (ComD) that binds the extracellular cognate CSPs, leading to the phosphorylation of the response regulator ComE $[4,5]$. The XIP class is used by most other streptococci, and is transported inside the cells by Opp oligopeptide permeases, leading to the activation of intracellular Rgg-type regulators [6, 7, 8, 9]. The last class, comprising bacteriocin-inducing peptides, is only known in $S$. mutans. Although primarily involved in bacteriocin induction, these peptides, also named CSPs, do induce competence, but in contrast to the CSP-class in the mitis and anginosus groups, they act indirectly by stimulating the XIP-class $[10,11]$. All classes of pheromones lead, ultimately, to the induction of the alternative sigma factor SigX, which then induces the expression of competence genes required for DNA uptake and recombination.

Spontaneous competence development under laboratory conditions is in practice not always reliable, and subtle changes in factors such as medium batch, medium composition, $\mathrm{pH}$, and growth temperatures, may dramatically affect competence levels [12, 13]. The introduction of synthetic pheromones in protocols for natural transformation has overcome many of these 
difficulties, by bypassing stringent conditions for production and secretion of natural pheromones, and by prolonging the transient nature of the competent state in streptococci [5]. The higher transformation efficiencies and reproducible results usually achieved with synthetic pheromones can be further optimized by the choice of growth medium and DNA donor, to reach levels that allow the practical use of markerless strategies for direct genome editing, as recently demonstrated for S. mutans and S. pneumoniae (see Chapter 14) [14].

This chapter describes transformation protocols for oral streptococci based on competence stimulated by synthetic pheromones. We present examples of optimized assays for S. mutans UA159 (XIP and bacteriocin-inducing classes of pheromones) and the S. mitis type strain CCUG $31611^{\mathrm{T}}$ (CSP class of pheromone), and general protocols with CSP that have been used for other strains of the mitis group, as well as for the anginosus group. These can be used as starting points for transformation of other streptococcal strains and species for which optimal protocols have not yet been established.

\section{Materials}

\subsection{Competence Induction Using Synthetic Peptides}

1. Agar plates: Todd-Hewitt Broth (THB) 30 g/L (Difco Laboratories, Detroit, MI, USA). Add $15 \mathrm{~g} / \mathrm{L}$ of agar to the medium (VWR Chemicals, Radnor, PA, USA), and autoclave at $121^{\circ} \mathrm{C}$ for $15 \mathrm{~min}$. For selective agar plates, the appropriate antibiotic(s) should be added to the medium once it has cooled to below $60{ }^{\circ} \mathrm{C}$, and the media should be stored under conditions appropriate for the antibiotics (see Note 1).

2. Liquid media: For transformation of S. mutans: Tryptone Soya Broth (Thermo Scientific, Waltham, MA, USA)) $30 \mathrm{~g} / \mathrm{L}$ is used for stimulation with CSP. For stimulation 
with XIP, chemically defined medium (CDM) [15], prepared from concentrated stock solutions with $1 \%$ glucose is used for growth, stock preparation of streptococcal pre-cultures and transformation assays; for transformation of the anginosus group: THB-HS broth comprising Todd Hewitt Broth (THB; Difco Laboratories) supplemented with 2-10 \% (v/v) heat-inactivated horse serum (HS); for transformation of Streptococcus mitis: C + Y YB [16], a chemically defined medium derived from the previously described $C+Y$ medium [17], but with an increased concentration of yeast extract and bovine serum albumin; for other oral streptococci: THY (see Notes $2-4$ ).

3. Synthetic peptides: Synthetic pheromones specific for the strain or species used may be ordered from peptide synthesis services. Examples of pheromones that have been used in transformation of streptococci are shown in Table 1. A stock solution of CSP is prepared by resuspending the lyophilized peptide in distilled water to a concentration of $10 \mathrm{mM}$, and storing it at $-20{ }^{\circ} \mathrm{C}$. Working solutions of 10 or $100 \mu \mathrm{M}$ are aliquoted and stored at $-20{ }^{\circ} \mathrm{C}$. Lyophilized XIP (GenScript, Piscataway, NJ, USA) is reconstituted with $20 \mu \mathrm{L}$ dimethyl sulfoxide (DMSO) (Sigma-Aldrich, St. Louis, MI, USA) to which $1 \mathrm{~mL}$ distilled water is added to give a final concentration of $10 \mathrm{mM}$ (stored at $-20^{\circ} \mathrm{C}$ ). Working stocks are prepared at $100 \mu \mathrm{M}$ by dilution in distilled water (see Note 5). For the CSP and XIP sequences, see Subheading 3.3, step 4 .

4. DNA donor: Amplicons and replicative plasmid used in the experiments are listed in Table 2. For maximal recovery of transformants, use purified DNA at saturation levels (see Notes 6 and 9). 
5. DNaseI (Roche, DNaseI recombinant, $10 \mathrm{U} / \mu \mathrm{L}$ ): DNaseI is used to degrade DNA not taken up by the cells. This step is usually omitted if the aim is to obtain maximal number of transformants.

\section{Methods}

Compared with protocols based on spontaneous competence, the use of synthetic pheromones leads often to higher transformation efficiencies, a better control over the time of competence development, and may extend transformation to a wider range of strains. The peptides are stable, and offer a straightforward approach for transformation of strains in which the pheromone sequence is known.

We present two protocols for transformation of $S$. mutans, the first optimized for transformation by XIP using CDM as the growth medium [14]. The high efficiency of this method is particularly useful for direct markerless construction of mutants (see Chapter 14). The second protocol involves the use of synthetic CSP (bacteriocin-inducing class) in rich medium. Although only a fraction of the $S$. mutans population becomes competent in rich medium, compared with stimulation by XIP in CDM, transformation can reach levels sufficiently high for marker-based constructions [11, 18]. The advantage of using rich medium such as TSB is that there is no need for the availability of an extensive list of ingredients such as that used for CDM preparation and it is much simpler to prepare.

Genetic manipulation of $S$. mitis by natural transformation is known to be challenging. Here, we present a procedure for S. mitis transformation in THB-HS broth and an optimized protocol using a semi-defined medium known to support endogenous competence. 
In the mitis group, CSPs often vary among the different species and strains. Thus, it may be necessary to characterize the CSP-encoding gene in strains for which the CSP sequence is unknown. Strategies that have been used for CSP gene identification based on PCR amplification and sequencing are therefore presented.

\subsection{Transformation efficiency /kinetics protocol using synthetic XIP in CDM in S. mutans}

Given the influence of (i) as yet undefined environmental conditions, (ii) the transient nature of competence, and (iii) strain to strain variations in transformation efficiencies, one may choose to run kinetic experiments before establishing routine transformation protocols. The following protocol has been used to determine the kinetics of competence development in S. mutans UA159 using synthetic XIP and PCR amplicon with antibiotic marker as donor DNA (see Fig. 1).

1. Stock cultures are stored at $-80^{\circ} \mathrm{C}$ or $-20^{\circ} \mathrm{C}$ in $30 \%$ glycerol.

2. Plate the desired bacteria on THB agar plates. Incubate at $37^{\circ} \mathrm{C}$ overnight in $5 \% \mathrm{CO}_{2}$.

3. Preparation of pre-cultures: Inoculate 3 to 10 colonies using a sterile transfer loop in 5 $\mathrm{mL}$ of $\mathrm{CDM}$. Incubate at $37^{\circ} \mathrm{C}$ in $5 \% \mathrm{CO}_{2}$ for 3 to $4 \mathrm{~h}$ or until absorbance at $600 \mathrm{~nm}$ $\left(\mathrm{A}_{600}\right)=\sim 0.5$. Store the cells in $15 \%$ glycerol at $-70^{\circ} \mathrm{C}$ or use it directly in the transformation experiments (see Note 7).

4. Dilute the pre-culture culture 1:10 in $\operatorname{CDM}\left(\mathrm{A}_{600}=\sim 0.05\right)$ and incubate at $37^{\circ} \mathrm{C}$ in air. Thaw the specific CSP on ice while waiting for the next step.

5. After 1.5-2 h incubation $\left(\mathrm{A}_{600}=\sim 0.08-0.1\right.$ or $\left.\mathrm{CFU}=\sim 7 \times 10^{6} / \mathrm{mL}\right)$, add XIP (see Table 1) to the culture to a final concentration of $1 \mu \mathrm{M}$, and continue incubating at $37^{\circ} \mathrm{C}$ in air (see Note 8). 
6. Add 50 to $100 \mathrm{ng}$ donor DNA to a $100 \mu \mathrm{L}$ aliquot of cells at different time points (see Fig. 1). Mix it by gently tapping the base of the microfuge tube or gently stir with a micropipette tip. Incubate the culture at $37^{\circ} \mathrm{C}$ for $20 \min$ (see Notes 9 - 11).

7. Add $200 \mu \mathrm{L}$ of warm CDM containing $20 \mathrm{U} / \mathrm{mL}$ DNaseI (Roche, DNaseI recombinant, $10 \mathrm{U} / \mu \mathrm{L}$ ) to each aliquot of the competent cells, and proceed with incubation at $37^{\circ} \mathrm{C}$ in air for another $40 \mathrm{~min}$.

8. Spread 20 to $200 \mu \mathrm{L}$ from serial dilutions of the transformation mix on selective or nonselective THB agar plates. Wait for the liquid to dry on the agar. Invert the plates and incubate them at $37^{\circ} \mathrm{C}$ in $5 \% \mathrm{CO}_{2}$ for $24-48 \mathrm{~h}$.

9. Count the colonies in each plate and calculate the transformation efficiency using the formula below:

Transformation efficiency $(\%)=\underline{\text { CFU transformants } \times 100}$

\section{Total CFU}

10. Select at least three colonies (putative transformants) for further characterization. The colonies should be individually transferred to separate tubes with fresh TSB containing the appropriate antibiotic and incubated at $37^{\circ} \mathrm{C}$ in $5 \% \mathrm{CO}_{2}$ for $24 \mathrm{~h}$.

11. Screen the colonies to verify whether the DNA construct was correctly incorporated in the mutant. Methods based on PCR using primers designed to provide amplicons that distinguish the mutants from the wild-type may be used for this purpose. Carry out the next two steps if the mutants will be used in downstream applications.

12. Plate the selected bacteria in the presence of the antibiotic and incubate them at $37^{\circ} \mathrm{C}$ in $5 \% \mathrm{CO}_{2}$ for $24-48 \mathrm{~h}$. Ensure at least two passages in antibiotic-containing media (see Note 12). 
13. Grow the selected bacteria in THB until exponential phase is reached, and store the culture in $15 \%$ glycerol at $-20^{\circ} \mathrm{C}$ or $-70^{\circ} \mathrm{C}$.

\subsection{Transformation protocols for downstream applications using synthetic pheromones}

These are simplified protocols that we have used in experiments in which determination of the kinetics of competence are not the focus, or in which acceptable efficiency levels are obtained without the need for further optimization steps.

\subsubsection{Streptococcus mutans}

\subsubsection{Transformation using synthetic CSPs in rich medium}

This protocol has been used for transformation of different $S$. mutans strains using DNA with antibiotic marker (see Note 13).

1. Follow steps 1 and 2 described in Subheading 3.1.

2. Inoculate 3-10 colonies using a sterile transfer loop in $5 \mathrm{~mL}$ of $\mathrm{TSB}$. Incubate at $37^{\circ} \mathrm{C}$ in $5 \% \mathrm{CO}_{2}$ for 3 to $4 \mathrm{~h}\left(\mathrm{~A}_{600}=\sim 0.5\right)$. Store the cells in $15 \%$ glycerol at $-80^{\circ} \mathrm{C}$ or use it directly in the transformation experiments.

3. Dilute the pre-culture $1: 10$ in TSB and prepare $500 \mu \mathrm{L}$ to $1000 \mu \mathrm{L}$ aliquots in $1.5 \mathrm{~mL}$ Eppendorf tubes. Add 18-CSP to a final concentration of $50 \mathrm{nM}$ and donor DNA, and incubate at $37^{\circ} \mathrm{C}$ in air for 2.5 to $3 \mathrm{~h}$ (see Notes 4 and 9).

4. Follow the steps 8-13 described in Subheading 3.1.

\subsubsection{Streptococcus mitis}

Here we present two protocols: one optimized protocol in semi-defined medium, and other in THB-HS medium. By following the protocol in semi-defined medium using a 7-kb PCR 
amplicon as donor DNA, we achieved 30-40\% transformation efficiency while in THB-HS the efficiency was only $\sim 0.01 \%$. (see Fig. 2) (see Note 4).

\subsubsection{Transformation Using Synthetic CSP in C+Y $+Y_{Y B}$ medium}

This protocol has been optimized for transformation of the S. mitis type strain CCUG 31611 (corresponds to NCTC 12261). Pre-culture preparation:

1. Plate the desired bacteria in a blood plate without antibiotics. Incubate at $37^{\circ} \mathrm{C}$ overnight in $5 \% \mathrm{CO}_{2}$.

2. Pre-culture preparation: Inoculate 3 to 10 colonies using a sterile transfer loop in $5 \mathrm{~mL}$ of TSB. Incubate at $37^{\circ} \mathrm{C}$ in $5 \% \mathrm{CO}_{2}$ for 3 to $4 \mathrm{~h}\left(\mathrm{~A}_{600}=\sim 0.5\right)$. Store the cells in $15 \%$ glycerol at $-80^{\circ} \mathrm{C}$ or use it directly in the transformation experiments (see Note 7).

Transformation:

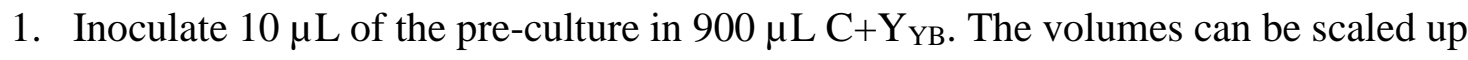
but the 1:100 dilution should be maintained.

2. Incubate at $37^{\circ} \mathrm{C}$ in $5 \% \mathrm{CO}_{2}$ for 2 to $3 \mathrm{~h}\left(\mathrm{~A}_{600}=\sim 0.04\right)$.

3. Add CSP at a final concentration of $300 \mathrm{nM}$ and donor DNA. Saturated concentrations for DNA are in the range of 100 to $150 \mathrm{ng}$ per $\mathrm{mL}$ for PCR amplicons and above 10 $\mu \mathrm{g}$ for genomic DNA and above $1 \mu \mathrm{g}$ for plasmid DNA (pVA838).

4. Incubate at $37^{\circ} \mathrm{C}$ in air for $3 \mathrm{~h}$ (see Note 8 ).

5. Follow the steps 8-13 as described in Subheading 3.1 for S. mutans.

\subsubsection{Transformation using synthetic CSP in rich medium}

Pre-culture preparation:

1. Inoculate $5 \mathrm{ml}$ THY with $\sim 10 \mu \mathrm{L}$ of the stock culture using a sterile transfer loop, and incubate at $37^{\circ} \mathrm{C}$ overnight in $5 \% \mathrm{CO}_{2}$ microaerophilic atmosphere. 
2. Dilute the $\mathrm{ON}$ culture 1:100 in THY and incubate at $37^{\circ} \mathrm{C}$ in a $5 \% \mathrm{CO}_{2}$ atmosphere for 4 to $5 \mathrm{~h}\left(\mathrm{~A}_{600}=\sim 0.3\right)$. Store the cells in $10 \%$ glycerol at $-70^{\circ} \mathrm{C}$, or use it directly in the transformation experiments.

Transformation:

1. Inoculate $100 \mu \mathrm{L}$ of the pre-culture in $900 \mu \mathrm{L}$ THB-HS. The volumes can be scaled up but the 1:10 dilution should be maintained.

2. Add CSP at a final concentration of $200 \mathrm{nM}$ and transforming DNA at the concentration described above. Incubate at $37^{\circ} \mathrm{C}$ in air for $3-4 \mathrm{~h}$ (see Note 8).

3. Follow the steps 7 - 12 described in Subheading 3.1.

\subsubsection{The Anginosus Group: Streptococcus intermedius, Streptococcus anginosus, and}

\section{Streptococcus constellatus}

This protocol, slightly modified from Gaustad and Morrison [19], has allowed transformation of S. intermedius, S. anginosus, and S. constellatus (see Notes 4 and 15). This protocol uses THB-HS, but TSB can also be used [20].

1. Stock cultures are stored at $-80^{\circ} \mathrm{C}$ or $-20^{\circ} \mathrm{C}$ in $30 \%$ glycerol.

2. Inoculate $5 \mathrm{~mL}$ THB-HS with $\sim 10 \mu \mathrm{L}$ of the stock culture using a sterile transfer loop and incubate at $37^{\circ} \mathrm{C}$ overnight in a $5 \% \mathrm{CO}_{2}$ (in air) atmosphere.

3. Dilute the overnight culture 1:10 in THB-HS and prepare $500 \mu \mathrm{L}$ to $1000 \mu \mathrm{L}$ aliquots in 1.5 mL Eppendorf tubes. Incubate at $37^{\circ} \mathrm{C}$ in air for $1-1.5 \mathrm{~h}$. Thaw the specific CSP on ice while waiting for the next step. (see Note 16)

4. Add the CSP and DNA donor to the culture to a final concentration of $20-50 \mathrm{nM}$ and allow growing at $37^{\circ} \mathrm{C}$ in air for $1 \mathrm{~h}$, followed by $37^{\circ} \mathrm{C}$ in $5 \% \mathrm{CO}_{2}$ for $1-3 \mathrm{~h}$.

5. Follow the steps 8 to 13 described in Subheading 3.1. 


\subsubsection{Other oral streptococci}

The protocol used for the anginosus group (Subheading 3.2.3) may also be applicable to $S$. gordonii, S. sanguinis, and other oral streptococci [19]. The following modified assay that allows $S$. gordonii stocks to be stored in frozen aliquots, and directly applied in competence experiments has been suggested [21]:

Pre-culture preparation:

1. Add $10 \mu \mathrm{g} / \mathrm{mL}$ synthetic CSP to overnight cultures grown at $37^{\circ} \mathrm{C}$ in $\mathrm{THY}$ supplemented with chloramphenicol $(5 \mu \mathrm{g} / \mathrm{mL})$.

2. Freeze the cells in $100 \mu \mathrm{L}$ aliquots following the addition of $10 \%$ glycerol. Transformation:

1. Add $900 \mu \mathrm{L}$ THY to $100 \mu \mathrm{L}$ of the frozen cell aliquot.

2. Add transforming DNA, and incubate the cells at $37^{\circ} \mathrm{C}$ for $3 \mathrm{~h}$.

3. Follow the steps 8 - 13 described in Subheading 3.1.

\subsection{Synthetic CSPs: sequence identification}

Verify whether the pheromone for the strain you will be working with has been previously identified. Some of the CSPs and XIPs that have been used for transformation of oral streptococci are presented in Table 1. For updated information on other strains, search gene/protein databases such as Entrez. If the pheromone in your chosen strain has not yet been identified, you may use PCR to amplify and sequence the gene for the competence pheromone. This information is then used to predict the pheromone amino acid sequence for your strain.

1. In S. mutans, the com C and comS genes encoding the CSP and XIP pheromones, respectively, are highly conserved [22]. Thus, the 18-CSP and the XIP for S. mutans UA159 shown in Table 2 should function for most, if not all, other S. mutans strains. 
In the mitis group, there is a large variation of CSP pheromones, particularly among $S$. mitis strains, whereas in the anginosus group of streptococci different species may produce the same pheromone. In these two groups, the CSP-encoding ( $\operatorname{com} C$ ) gene has been identified by using primers annealing to conserved Arg-tRNA and Glu-tRNA genes flanking the $\operatorname{comCDE}$ operon [4]. In this case, the primer pair t-Arg 5'GGCGGTGTCTTAACCCCTTGACCAACGGACC and t-Glu 5'CATAGCTCAGCTGGATAGAGCATTCGCCTTC is expected to amplify a fragment of approximately 2.5 to $2.6 \mathrm{~kb}$ [4]. For sequencing, the final reaction volume of $25 \mu \mathrm{L}$ should contain 200-300 ng chromosomal DNA, Taq Polymerase or a high-fidelity DNA polymerase such as $P f u$ at the recommended concentration, $0.2 \mathrm{mM} d \mathrm{NTP}, 1 \times$ PCR buffer containing standard $\mathrm{MgCl}_{2}$ concentration, and $0.1 \mu \mathrm{M}$ of each forward and reverse primer. The following cycle parameters for amplication of comC in $S$. mutans may be used: $94^{\circ} \mathrm{C}$ for $3 \mathrm{~min} ; 36$ cycles of $94^{\circ} \mathrm{C}$ for $30 \mathrm{~s}, 60^{\circ} \mathrm{C}$ for $30 \mathrm{~s}$ and $72^{\circ} \mathrm{C}$ for 30s; and a final polymerization step of $72^{\circ} \mathrm{C}$ for $7 \mathrm{~min}$. Adjust the PCR conditions for amplification of the com $C D E$ operon in the other oral streptococci by replacing the 30s extension time at $72^{\circ} \mathrm{C}$ with 2 min during the 36 cycles (see Note 17).

2. Verify the presence of the amplified product by electrophoresis in a $0.7 \%(\mathrm{w} / \mathrm{v})$ agarose gel, and determine the $\operatorname{com} C$ sequence in the amplified product, which by using the primers indicated above is within $\sim 350 \mathrm{bp}$ from the 5 '-end in other streptococci.

3. To predict the CSP sequence you may align the sequence of your amplified product with previously identified $\operatorname{com} C$ genes. Most often, the deduced CSP peptide sequence, when translated from your PCR product, is preceded by a double glycine cleavage site. Alignment of ComC with peptides of known cleavage sites may help 
define the mature peptide sequence [4]. Many peptide synthesis services are currently available, making the acquisition of the peptides convenient and affordable.

\section{Notes}

1. Brain Heart Infusion (BHI), TSB, or blood agar plates may also be used. The following antibiotic concentrations were used: kanamycin (Kan) $500 \mu \mathrm{g} / \mathrm{mL}$, and erythromycin (Erm) $10 \mu \mathrm{g} / \mathrm{mL}$.

2. Competence for natural transformation persists for a longer time in CDM using XIP when compared to TSB with CSP (see Fig. 1). Other media that have been used in S. mutans CSP transformation assays include BHI-HS [23] and THY-HS [24]. For markerless constructions we recommend to transform $S$. mutans in CDM with XIP as detailed in

\section{Chapter 14.}

3. We have had a previous experience in which a particular TSB batch resulted in very poor streptococcal transformation efficiencies, a problem that was solved by simply changing the batch of TSB used.

4. In choosing the medium for transformation, one important factor to consider is the mechanism used by streptococci to sense the different pheromones. For instance, when using XIP, a peptide-free medium is advantageous because other peptides present in the medium compete with XIP for transport into the cells.

5. Crude desalted XIP of $>80 \%$ purity is usually highly active.

6. Specific commercial DNA purification kits can be used for isolation of plasmids, PCR amplified fragments or genomic DNA, following the recommended DNA isolation protocols. Lysis procedures for oral streptococci should take into consideration the rigidity of the streptococcal cell wall. For S. mutans, we usually incubate the cells (up to $10^{9}$ cells) for $20 \mathrm{~min}$ in the presence of $100 \mathrm{U} / \mathrm{mL}$ mutanolysin and $20 \mathrm{mg} / \mathrm{mL}$ 
lysozyme. In trying alternative methods, the purity of the isolated DNA, which may impact on transformation efficiency, should be considered.

7. It is our experience that pre-cultures prepared from fresh colonies give higher transformation efficiencies, although we have not assessed it systematically (see Subheading 3.1).

8. Although streptococcal transformation protocols usually recommend growth of the cells in $5 \% \mathrm{CO}_{2}$, we usually obtain higher transformation efficiency levels when the cells are simply grown in air.

9. The transient nature of competence should be considered in kinetic studies. In S. mutans, the competent state may often last for more than $4 \mathrm{~h}$ in CDM, but in TSB transformation is finished around this time (see Fig. 1). In S. mitis, for instance, competence lasts for about 1 hour in $\mathrm{C}+\mathrm{Y}_{\text {YB }}$ (data not shown). The onset of competence may also vary, with $S$. gordonii exhibiting an almost immediate response to CSP [25], whereas in $S$. mutans a delay in competence induction response is observed $[23,26]$. This is because the CSP in S. mutans acts first by stimulating bacteriocin response before competence is triggered.

10. Saturating levels of amplicon DNA donor for S. mutans were experimentally determined and a final concentration of $75 \mathrm{ng} / \mathrm{mL}$ was shown to saturate the reaction [14]. Transformation efficiency determined in two experiments using saturation amounts of amplicon DNA donor (no addition of DNase) shows that efficiencies from $20 \%$ to $50 \%$ are often achieved (see Fig. 3).

11. The use of positive and negative controls is highly recommended, particularly during the construction of new mutants. A negative control will provide information on the selective activity of the antibiotics. Positive controls are usually DNA donor with an antibiotic resistance marker that is known to transform the target strain. The routine use 
of the same positive control allows comparison of the transformation efficiency between different experiments.

12. The repeated passage in media with the relevant antibiotic is conducted to avoid carry over of non-transformed bacteria. This step is particularly pertinent when using selection markers conferring resistance to antibiotics that are bacteriostatic (i.e., those that inhibit the growth of the cells without killing them). For selection of markerless mutants, we refer to Chapter 14.

13. The synthetic 18-CSP (SGSLSTFFRLFNRSFTQA), analogous to the peptide found in the supernatant of $S$. mutans, induces maximal competence at $20 \mathrm{nM}$ [27], but it may be used at concentrations as high as $1000 \mathrm{nM}$ without compromising transformation efficiency. The synthetic 21-CSP (SGSLSTFFRLFNRSFTQALGK) predicted from the comC sequence has often been used, but a delay in competence may be observed because this form of the peptide needs further processing by $S$. mutans into the 18-CSP active form.

14. S. mitis CCUG $31611^{\mathrm{T}}$ synthetic CSP (EIRQTHNIFFNFFKRR) has shown to induce maximal number of transformants by using a final concentration of 200-300 nM (data not shown)

15. We have used this protocol to obtain consistent transformation levels of the $S$. intermedius, S. anginosus, and S. constellatus type strains, and S. intermedius CCUG 28205.

16. The type strains of $S$. intermedius, $S$. anginosus, and $S$. contellatus respond to the same pheromone (see Table 1). However, analyses of recent genome sequence for these species reveal that this is not always the case. This information should be checked before deciding which pheromone is going to be used. 
17. The PCR strategy to identify the CSPs will depend on the presence of the flanking regions annealing to the specified primers. Different sequences or gene arrangements may, therefore, escape detection. Note that among the transformable oral streptococci, it is only in S. mutans that the $\operatorname{com} C$ gene is not flanked by the Arg-tRNA and GlutRNA genes.

\section{Acknowledgments}

This work was partially supported by the National Science Foundation, grant no. MCB1020863, by the Faculty of Dentistry, University of Oslo, and by the Norwegian surveillance system for antibiotic resistance in microbes (Norsk overvåkingssystem for antibiotikaresistens hos mikrober- NORM).

\section{References}

1. Federle MJ, Morrison DA (2012) One if by land, two if by sea: signalling to the ranks with CSP and XIP. Mol Microbiol 86:241-245

2. Fontaine L, Wahl A, Flechard M, Mignolet J, Hols P (2015) Regulation of competence for natural transformation in streptococci. Infection, genetics and evolution $\mathrm{J}$ Mol Epidemiol Evol Genet Infect Dis 33:343-360

3. Johnsborg O, Eldholm V, Håvarstein LS (2007) Natural genetic transformation: prevalence, mechanisms and function. Res Microbiol 158:767-778

4. Håvarstein LS, Hakenbeck R, Gaustad P (1997) Natural competence in the genus Streptococcus: evidence that streptococci can change pherotype by interspecies recombinational exchanges. J Bacteriol 179:6589-6594 
5. Morrison DA (1997) Streptococcal competence for genetic transformation: regulation by peptide pheromones. Microb Drug Resist 3:27-37

6. Khan R, Rukke HV, Ricomini Filho AP, Fimland G, Arntzen MO, Thiede B, Petersen FC (2012) Extracellular identification of a processed type II ComR/ComS pheromone of Streptococcus mutans. J Bacteriol 194:3781-3788

7. Mashburn-Warren L, Morrison DA, Federle MJ (2010) A novel double-tryptophan peptide pheromone controls competence in Streptococcus spp. via an Rgg regulator. Mol Microbiol 78589-606

8. Fontaine L, Boutry C, de Frahan MH, Delplace B, Fremaux C, Horvath P, Boyaval P, Hols P (2010) A novel pheromone quorum-sensing system controls the development of natural competence in Streptococcus thermophilus and Streptococcus salivarius. J Bacteriol 192:1444-1454

9. Monnet V, Juillard V, Gardan R (2016) Peptide conversations in Gram-positive bacteria. Crit Rev Microbiol 42:339-351

10. Lemme A, Grobe L, Reck M, Tomasch J, Wagner-Dobler I (2011) SubpopulationSpecific transcriptome analysis of competence stimulating peptide induced Streptococcus mutans. J Bacteriol 193:1863-1877

11. Son M, Shields RC, Ahn SJ, Burne RA, Hagen SJ (2015) Bidirectional signaling in the competence regulatory pathway of Streptococcus mutans. FEMS Microbiol Lett 362:doi: 10.1093/femsle/fnv159

12. Chen JD, Morrison DA (1987) Modulation of competence for genetic transformation in Streptococcus pneumoniae. J Gen Microbiol 133:1959-1967

13. Son M, Ghoreishi D, Ahn SJ, Burne RA, Hagen SJ (2015) Sharply tuned pH response of genetic competence regulation in Streptococcus mutans: a microfluidic study of the environmental sensitivity of comX. Appl Environ Microbiol 81:5622-5631 
14. Morrison DA, Khan R, Junges R, Amdal HA, Petersen FC (2015) Genome editing by natural genetic transformation in Streptococcus mutans. J Microbiol Methods 119:134141

15. Chang JC, LaSarre B, Jimenez JC, Aggarwal C, Federle MJ (2011) Two group A streptococcal peptide pheromones act through opposing Rgg regulators to control biofilm development. PLoS Pathogens 7:e1002190

16. Stevens KE, Chang D, Zwack EE, Sebert ME (2011) Competence in Streptococcus pneumoniae is regulated by the rate of ribosomal decoding errors. mBio 2:doi: 10.1128/mBio.00071-11

17. Lacks S, Hotchkiss RD (1960) A study of the genetic material determining an enzyme in Pneumococcus. Biochim Biophys Acta 39:508-518

18. Reck M, Tomasch J, Wagner-Dobler I (2015) The alternative sigma factor SigX controls bacteriocin synthesis and competence, the two quorum sensing regulated traits in Streptococcus mutans. PLoS Genet 11:e1005353

19. Gaustad P, Morrison DA (1998) Induction of transformation in streptococci by synthetic competence stimulating peptides. Methods Cell Sci 20:65-70

20. Petersen FC, Pecharki D, Scheie AA (2004) Biofilm mode of growth of Streptococcus intermedius favored by a competence-stimulating signaling peptide. J Bacteriol $186: 6327-6331$

21. Warren TK, Lund SA, Jones KF, Hruby DE (2007) Comparison of transformation protocols in Streptococcus gordonii and evaluation of native promoter strength using a multiple-copy plasmid. Can J Microbiol 53:417-426

22. Palmer SR, Miller JH, Abranches J, Zeng L, Lefebure T, Richards VP, Lemos JA, Stanhope MJ, Burne RA (2013) Phenotypic heterogeneity of genomically-diverse isolates of Streptococcus mutans. PLoS One 8:e61358 
23. Ahn SJ, Wen ZT, Burne RA (2006) Multilevel control of competence development and stress tolerance in Streptococcus mutans UA159. Infect Immun 74:1631-1642

24. Li YH, Lau PC, Lee JH, Ellen RP, Cvitkovitch DG (2001) Natural genetic transformation of Streptococcus mutans growing in biofilms. J Bacteriol 183:897-908

25. Vickerman MM, Iobst S, Jesionowski AM, Gill SR (2007) Genome-wide transcriptional changes in Streptococcus gordonii in response to competence signaling peptide. J Bacteriol 189:7799-7807

26. Kreth J, Merritt J, Shi W, Qi F (2005) Co-ordinated bacteriocin production and competence development: a possible mechanism for taking up DNA from neighbouring species. Mol Microbiol 57:392-404

27. Petersen FC, Fimland G, Scheie AA (2006) Purification and functional studies of a potent modified quorum-sensing peptide and a two-peptide bacteriocin in Streptococcus mutans. Mol Microbiol 61:1322-1334 
Table 1. Sequence of CSP and XIP from selected strains of oral streptococci for which the synthetic pheromones have been shown to induce competence.

XIP

Group Strain $\quad$ CSP sequence $^{\mathrm{a}} \quad$ sequence

Mutans S. mutans UA159

SGSLSTFFRLFNRSFTQA

GLDWWSL

$(18-\mathrm{CSP})$

SGSLSTFFRLFNRSFTQALGK

(21-CSP)

Salivarius

S. salivarius JIM8777/CCHSS3 ${ }^{\mathrm{G}}$

PYFTGCL

S. vestibularis ACTC 49124/FO396

PFFMIYY

Mitis

S. mitis CCUG $31611^{\mathrm{TG}}$

EIRQTHNIFFNFFKRR

S. gordonii Challis $\mathrm{CH} 1^{\mathrm{G}}$

DVRSNKIRLWWENIFFNKK

S. gordonii NCTC $7865^{\mathrm{T}}$,

DIRHRINNSIWRDIFLKRK

S. sanguinis SK36 ${ }^{\mathrm{G}}$

DLRGVPNPWGWIFGR

S. oligofermentans LMG $21535^{\mathrm{T}}$

DSRNIFLKIKFKKK

S. cristatus ACTC $51100^{\mathrm{G}}$

DLRNIFLKIKFKKK

S. infantis ATCC $700779^{\mathrm{G}}$

DKRLTYFITNLFPKRKK

S. oralis $\mathrm{COL} 19^{\mathrm{G}}$

EMRLPKILRDFIFPRKK

Anginosus

S. anginosus NCTC $10713^{\mathrm{T}}$

DSRIRMGFDFSKLFGK

S. constellatus NCTC $11325^{\mathrm{T}}$

DSRIRMGFDFSKLFGK

S. intermedius NCTC $11324^{\mathrm{T}}$

DSRIRMGFDFSKLFGK 
${ }^{\text {a }}$ In $S$. mutans the CSP belongs to the class of bacteriocin-inducing peptides, and differs from the CSP class identified in the mitis and anginosus groups.

T; type strain

G; genome sequence available 
Table 2. List of strains, primers, plasmids and amplicons used in this study.

\begin{tabular}{ll}
\hline Strain & Description \\
\hline S. mitis CCUG31611 & Wild-type $S$. mitis biovar 1 type strain, corresponds to \\
& NCTC $12261^{\mathrm{T}}$ \\
S. mutans UA159 & Wild-type $S$. mutans UA159 \\
MI074 & CCUG31611, but $\Delta$ SM12261_0092::Kan; Kan ${ }^{\mathrm{R}}$ \\
SM045 & UA159, but $\Delta$ dexA::kan; Kan ${ }^{\mathrm{R}}$ \\
\hline Primers & Sequence (5' to 3') \\
\hline FP906 & ATTCACCCCAAAAAGTGCTG \\
FP907 & ATAATATGCGGACGCTGAGG \\
FP1163 & CATCTTGATAGCGTGGCTCA \\
FP1166 & TTGAATTGAGACGGATTGGA \\
\hline Plasmid & FP1163/FP1166 - 6.9 kb - Kan ${ }^{\mathrm{R}}$, from MI074 \\
\hline pVA838 & Marker \\
\hline Amplicon & Erm ${ }^{\mathrm{R}}$ \\
\hline
\end{tabular}




\section{Figures}
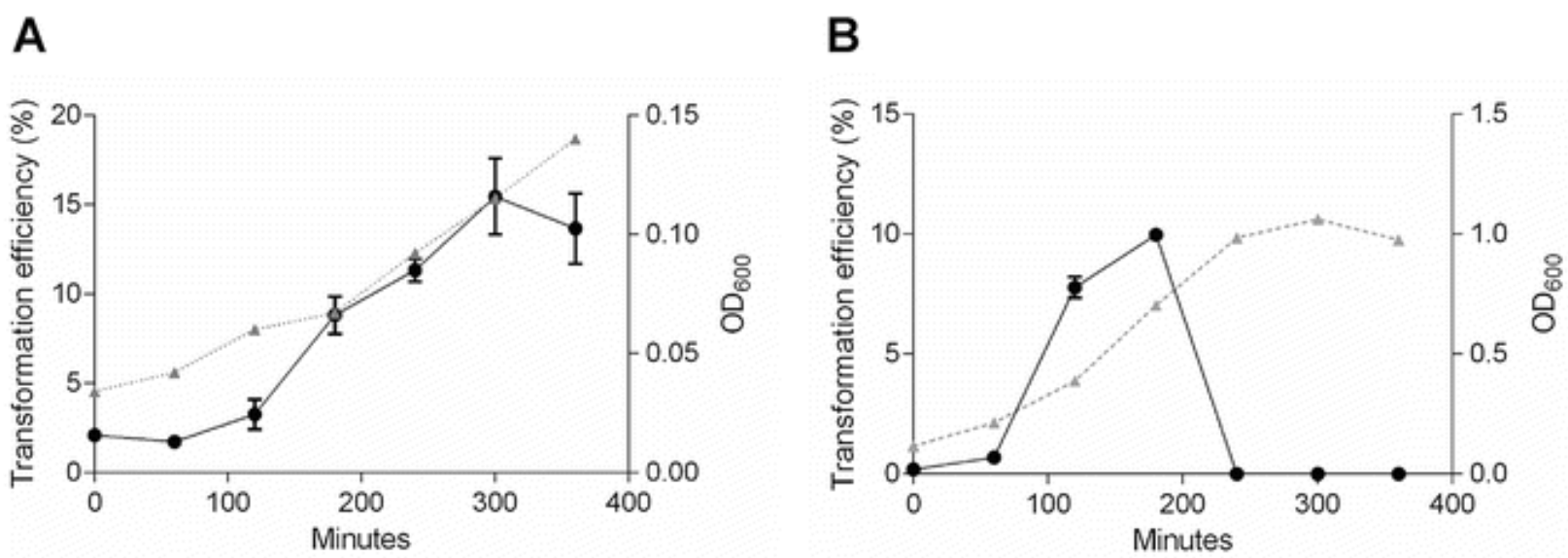

Fig. 1. Kinetics of Streptococcus mutans UA159 competence development in the presence of (A) synthetic XIP during growth in CDM and (B) synthetic CSP in TSB. Transformation used the 7-kb PCR amplicon (aRJ02) as donor DNA. The dots represent transformation efficiency values and the triangles are the corresponding absorbance values at $600 \mathrm{~nm}\left(\mathrm{~A}_{600}\right)$ of the growing culture corresponding to the time at which DNA was added, and are averages of three replicates. XIP or CSP was added at time "0". For each time point, DNase I was added after 20 min DNA exposure, and incubation proceeded for $40 \mathrm{~min}$ before plating the culture on non-selective and selective antibiotic plates. Bars represent standard error of the mean (SEM). 


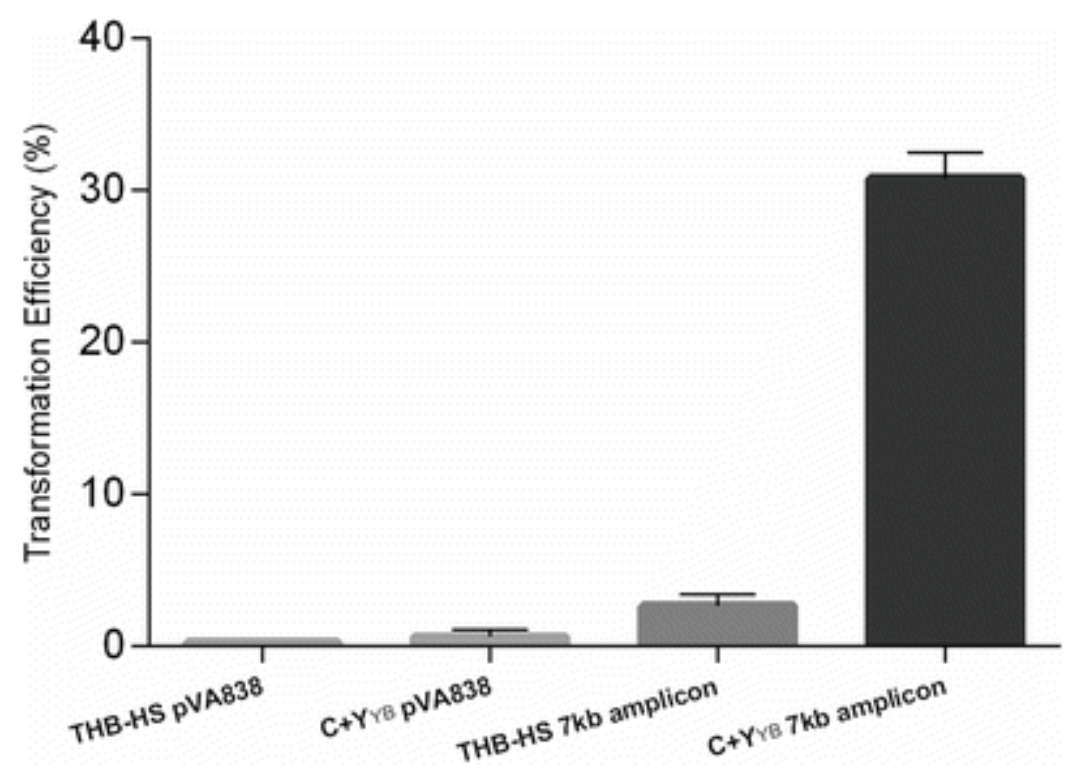

Fig. 2. S. mitis transformation in THB-HS or $\mathrm{C}+\mathrm{Y}_{\mathrm{YB}}$ using pVA838 $(1 \mu \mathrm{g} / \mathrm{mL})$ or a $7 \mathrm{~kb}$ amplicon (aRJ21) (150 ng/mL) as donor DNA, and CSP at a final concentration of $300 \mathrm{nM}$. Average of 3 replicates. Error bars represent standard error. 